\title{
O sujeito e o indivíduo na perspectiva de Alain Touraine
}

\author{
Marilia Veríssimo Veronese \\ Doutora em Psicologia Social (Pontifícia Universidade Católica do Rio Grande do Sul) \\ Professora na Universidade do Vale do Rio dos Sinos \\ mariliavero@yahoo.com.br \\ Luiz Felipe Barboza Lacerda \\ Mestre em Ciências Sociais (Universidade do Vale do Rio dos Sinos) \\ Professor na Universidade do Estado do Amazonas \\ luizpsico@hotmail.com
}

\begin{abstract}
Resumo Este artigo tem o intuito de discutir, a partir da perspectiva mais recente de Alain Touraine, o desenvolvimento dos processos de subjetivação na contemporaneidade. Busca-se compreender como as mudanças atuais na forma de perceber e estar no mundo influenciam a constituição do sujeito. Para isto, analisamos de que maneira o autor distingue os conceitos de indivíduo e sujeito, assim como a importância da relação existente entre a subjetividade humana nas suas manifestações singulares e os movimentos sociais e lutas por emancipações, travadas pelos diversos grupos e comunidades
\end{abstract}

Palavras-chave: indivíduo; sujeito; movimentos sociais.

\section{Introdução}

A busca por definições do contexto social que possibilitem A um território mínimo de localização teórica do sujeito na sociedade contemporânea é, hoje, tema fundamental nas ciências sociais. Encontramos diferentes modos de conceber o tempo presente e o passado recente que, de acordo com as diversas correntes teóricas, ganham denominações específicas. Como exemplos, alguns autores, como Maffesoli (2001), utilizam a terminologia "pós-moderno" para esquadrinhar as múltiplas possibilidades de ser e estar na contemporaneidade; outros ainda, como Lipovétsky (2006), sugerem uma concepção de hipermodernidade.

A distinção entre esses conceitos nem sempre é simples e por vezes o próprio corpo acadêmico admite posições e concepções diversas (e nem sempre claras) a respeito dessas terminologias. A importância de compreendê-los apresenta-se, justamente, pelo fato de não resumiremse apenas a nomenclaturas e categorizações, mas de trazerem em si, cada um de maneira peculiar, um modo de compreender o estar no mundo. Podemos empreender uma tentativa de ampliar a compreensão sobre a distinção entre conceitos de pré-moderno, moderno e pós-moderno a partir do quadro da página seguinte, adaptado do trabalho de Gadea (2007).

Para nossa finalidade específica, é importante apontar que a chamada pós-modernidade caracteriza-se muito mais por um modo de habitar e perceber o mundo moderno do que propriamente uma linear mudança de era, prescrita por uma profunda transformação nas estruturas sociais vigentes. Percebe-se isto na eventual postura relativista que os sujeitos as- 


\begin{tabular}{|c|c|c|c|}
\hline & Pré-Moderno & Moderno & Pós-Moderno \\
\hline CONDUTAS & $\begin{array}{l}\text { Passado (movimento } \\
\text { cíclico de retorno) }\end{array}$ & $\begin{array}{l}\text { Futuro (enfoque no destino; } \\
\text { linha ascendente, espiral e } \\
\text { linear) }\end{array}$ & $\begin{array}{l}\text { Presente (contingência, aqui e } \\
\text { agora) }\end{array}$ \\
\hline $\begin{array}{l}\text { RELAÇÃO COM O } \\
\text { TRANSCENDENTE }\end{array}$ & Religião & Razão (desencanto do mundo) & $\begin{array}{l}\text { Crise da razão } \\
\text { (reencantamento do mundo; } \\
\text { múltiplas razões) }\end{array}$ \\
\hline $\begin{array}{l}\text { CAMINHO DA } \\
\text { FELICIDADE }\end{array}$ & Místico contemplativo & Controle das pulsões e desejos & Dionisíaco - lúdico \\
\hline $\begin{array}{l}\text { CONCEPÇÃO DE } \\
\text { ORDEM SOCIAL }\end{array}$ & Hierárquica & $\begin{array}{l}\text { Princípio de igualdade } \\
\text { (que se transformou em } \\
\text { homogeneidade) }\end{array}$ & $\begin{array}{l}\text { Diferença (a multiplicidade é } \\
\text { que torna todos iguais, todos } \\
\text { múltiplos) }\end{array}$ \\
\hline $\begin{array}{l}\text { PRINCÍPIOS DE } \\
\text { VÍNCULAÇÃO }\end{array}$ & Afetividade & Funcionalidade & $\begin{array}{l}\text { Neoafetividade } \\
\text { (compartilhamento de coisas } \\
\text { comuns) }\end{array}$ \\
\hline $\begin{array}{l}\text { PRINCÍPIOS DE } \\
\text { LEGITIMIDADE DA } \\
\text { REALIDADE }\end{array}$ & Teologia & $\begin{array}{l}\text { Metarrelato explicativo } \\
\text { (concepções estruturalistas } \\
\text { como comunismo, capitalismo } \\
\text { etc) }\end{array}$ & $\begin{array}{l}\text { Múltiplos relatos e realidades } \\
\text { (relativização das escalas de } \\
\text { valores e verdades) }\end{array}$ \\
\hline $\begin{array}{l}\text { RELAÇÃO MUNDO- } \\
\text { PESSOA }\end{array}$ & Particular & Universal & Relativista \\
\hline
\end{tabular}

Fonte: Gadea (2007)

sumem, pois esta não concebe mais uma única verdade como legítima, mas sim que cada pessoa, cada lugar e cada acontecimento eventualmente possuem sua própria verdade.

A posição relativista aponta para a descrença em soluções oriundas dos discursos universalizantes, como a religião ou a razão. Esse modo de estar pósmoderno abre mão dos discursos totais e, por vezes, também da busca de soluções para os problemas do mundo, somente abrindo para as contradições e incertezas, o que faz Santos (2006) advertir para os perigos do abandono da ideia de emancipação. $\mathrm{O}$ autor tem argumentado, em seus trabalhos, que os problemas modernos continuam presentes (opressão, discriminações, desigualdades, concentração de riquezas), apesar de não acreditar mais nas soluções modernas, pois nem revolução nem reformismo deram conta de encaminhar essas distorções.

A desvinculação do indivíduo em relação a discursos universais ou totalizantes o libertou para a busca de sua própria verdade, ou poderíamos dizer autoverdade. Por um lado, esse movimento (contraditório) eventualmente gerou ondas de individualismo, posturas egocêntricas e orientações de ação utilitaristas, mas, por outro, possibilitou a cada um perceber-se como ser singular, diferente. Com isto, tornou-se possível desatar das instituições normatizantes que, através das maneiras discursivas universais, buscam inscrever o sujeito em certo rol de ações já esquadrinhadas. Este é o movimento que, cada vez mais, vem possibilitando o emergir de um devir sujeito em cada um de nós.

O presente artigo coloca-se, portanto, no intuito de discutir, principalmente a partir dos escritos de Alain Touraine em Um novo paradigma (2006), o desenvolvimento dos processos de subjetividade na contemporaneidade. Isto é, compreender de que maneira as mudanças atuais na forma de estar e perceber o mundo influenciam na formação de cada indivíduo, a partir da lente teórica desse autor. O texto de Touraine nos conduz a reflexões interessantes e pertinentes para tal estudo visto que, primeiramente, sugere uma perspectiva diferenciada na análise social. O autor coloca que "estamos saindo de uma época em que era a história o sujeito, até mesmo um pedaço da história recortada arbitrariamente do tempo histórico" (p. 133). Essa antiga tendência analítica, encontrada com frequência nas Ciências Sociais, garantia status de personagens reais para fenômenos históricos, omitindo assim a noção real do ator. "Eu próprio, num período de transição, falei do sujeito histórico, ao passo que hoje não quero falar senão do sujeito pessoal (o que não o reduz absolutamente aos casos sociais)" (p. 133). Essa perspectiva traz o ator como ponto de partida da análise social, o que representa uma perspectiva marcante nas concepções vigentes nas Ciências Sociais.

Ou seja, a partir da análise do singular, apresentam-se argumentos de contraposição às teorias que têm uma concepção do ator social como vítima de condições dificilmente insuperáveis, ou tidas como 
inevitáveis. Contrapõe-se às teorias estruturalistas, construindo uma concepção que busca a relativização do indivíduo e a libertação do sujeito, resgatando a perspectiva emancipatória, mas num contexto de pluralidade. Touraine afirma que "os que não veem ao seu redor senão vítimas e máquinas de dominação e de morte é que são os caolhos. Não veem, ao lado da injustiça e da morte, afirmar-se a vontade de lutar contra elas" (p. 123).

Por fim, chama a atenção a maneira como Touraine propõe a análise social partindo de um sujeito combatente, engajado e crítico (sem buscar traçar para esse personagem heróico um status de pleno construtor da realidade), ora com potencialidades afloradas, ora com maleabilidade e flexibilidade, inserido nas articulações sociais.

\section{Distintas percepções sobre o voltar-se a si mesmo}

Durante longo tempo, o ser humano buscou o sentido de sua vida numa ordem do universo ou numa ordem divina, numa cidade ideal ou numa sociedade de iguais, num progresso sem fim ou numa transparência absoluta. Mas, ao longo dos dois últimos séculos, em algum momento os céus esvaziaram-se de suas divindades, trocando-os por guardiões, ditadores, polícias secretas e mesmo, mais recentemente, por publicitários e executivos de grandes empresas (Touraine, 2006, p. 122).

$\mathrm{Na}$ medida em que triunfavam esses novos poderes, cada um era convidado a voltar-se a si mesmo, descobrindo-se dentro de uma realidade mais concreta: cidadãos, trabalhadores na busca de melhores condições de existência, mulheres em busca de liberdade. E, cada vez mais, constituíam-se como seres culturais, no intuito de resistir à mercantilização de todos os aspectos da vida, seres de gênero e de sexualidade mergulhados no mais profundo de si mesmos para escapar às ideologias e autoritarismos. Dessa forma, a raiz do sistema que tinha por base a padronização dos desejos sofre um golpe na medida em que se engendram resistências através da vontade e criatividade de sujeitos e grupos sociais (Guattari \& Rolnik, 1993).

$\mathrm{Na}$ ideologia neoliberal, predominante no Ocidente entre as décadas de 1980, 1990 e meados de 2000, foi estimulada uma postura individualista, produzindo a constituição de um sujeito capturado pelas estruturas vigentes, baseado em um pensamento "racional", popularizando-se uma vulgata utilitarista que assumia que o ser humano é egoísta, e isso era racional e até desejável. Guattari \& Rolnik (1993, p. 19) afirmam que "nas últimas décadas a produção capitalista se empenhou, ela própria, em produzir suas margens, e de algum modo equipou novos territórios subjetivos: os indivíduos, as famílias, os grupos sociais, as minorias. Tudo isso parece ser muito bem calculado".

Dessa forma, esse processo de voltar a si mesmo de maneira a perceber-se como fim último de sua própria ação acabaria desencadeando a identificação com o que Reis (1989) chama de Homo Economicus. O Homo Economicus é aquele homem que age racionalmente, sempre com rapidez e eficiência, pensando nas melhores formas de viabilizar e maximizar ganhos. Age por interesse próprio, dessa forma assumindo uma postura individualizada e competitiva. Ainda segundo Reis (1989, p. 3),

O predomínio da lógica econômica como ideologia, como valor, crença socialmente difundida, torna-se incontestável. O economicismo que impregna todo nosso raciocínio impõe a abstração o Homo Economicus [...] o indivíduo possessivo e egoísta que no afã de realizar suas paixões age de forma utilitária.

Contudo, Touraine, em contraposição a esse pensamento, aponta que é somente através desse voltar-se a si mesmo que a pessoa liberta-se das amarras que a prendem. É dessa perspectiva que o autor fará a distinção entre o sujeito e o indivíduo. Para Touraine, o indivíduo, de maneira geral, é aquele moldado pelos padrões sociais, uma figura que não passa de uma tela em branco onde são depositados desejos, necessidades, mundos imaginários a serem consumidos. Em contraposição, o sujeito é aquele que se revolta contra essa situação, é o devir combatente, rebelde, que se volta para si no intuito de buscar a única verdade possível: a sua.

Parece-nos que a aposta de Touraine em buscar algo de resistência na atitude de voltar-se a si mesmo provém justamente de sua visão não fatalista da realidade social. Apostando que ao lado de toda força que aprisiona constitui-se uma força de resistência, o autor busca a cartografia daquilo que considera o mais original em cada ser, e, consequentemente, o mais livre e potencialmente transformador da realidade social.

\section{O indivíduo e o sujeito}

Para Touraine, o sujeito evoca a ideia de luta social, semelhante à de consciência de classe, contudo enquanto esfera individual. O sujeito, portanto, configura-se como parte íntima de cada ser que possui como movimento a resistência, o confronto, o debate.

Só nos tornamos plenamente sujeitos quando aceitamos como nosso ideal reconhecer-nos - e fazer-nos 
reconhecer enquanto indivíduos - como seres individuados, que defendem e constroem sua singularidade, e dando, através de nossos atos de resistência, um sentido a nossa existência. (Touraine, 2006, p. 123)

Poderíamos, assim como faz Touraine ao longo do texto, nos perguntar: será que vivemos em um mundo de sujeitos ou de indivíduos? Com certeza, após rápida autoanálise, perceberemos que é, salvo algumas exceções, inviável manter-se o tempo todo na esfera do sujeito. Como ser sempre combatente, opositor, livre e questionador? Sabemos que a própria necessidade de convívio social nos impõe regras e condutas que não concordamos por completo, mas devem ser seguidas para que a convivência em sociedade seja possível (e nós eventualmente as seguimos, mesmo contra a vontade). Muitas vezes, não é barato o preço a ser pago por ser incessantemente sujeito. $\mathrm{Na}$ alternância entre ser e não ser sujeito, nós nos deparamos com a outra dimensão do ser descrita por Touraine, o indivíduo.

Ao indivíduo cabe a ordem dos direitos, dos deveres, da moralidade, é a parte em nós que transita em comum acordo com as regras e instituições sociais, a parte flexível, maleável, adaptável ao sistema. Ele é alvo dos direitos universais, políticos e culturais promovidos pelas instâncias públicas, constituindo-se como a parte formada, modelada socialmente.

O indivíduo não passa então de uma tela pela qual se projetam desejos, necessidades, mundos imaginários fabricados pelas novas indústrias da comunicação. Esta imagem de indivíduo que já não é mais definido por grupos de pertença, que é cada vez mais enfraquecida e que não encontra garantia de sua identidade em si mesmo, pois já não é mais um princípio de unidade e é obscuramente dirigido por aquilo que escapa sua consciência, serviu muitas vezes para definir a modernidade. (Touraine, 2006, p. 119)

Sobre o individualismo contemporâneo, podemos afirmar sua origem mais recente nos mecanismos especificamente modernos. Toda a base do pensamento moderno está definida segundo uma razão progressista, segundo a capacidade de um ser cognitivo que consegue, de forma deslocada do contexto, colocar a si mesmo como único fim. Cogito ergo sum seria a máxima moderna, a frase síntese da concepção de si que teve a modernidade como epistemologia (Jovchelovitch, 2004).

Visto que raramente encontramos figuras que se posicionam de maneira plena em seu aspecto sujeito, como se estabelece essa relação entre indivíduo e sujeito? Primeiramente é importante apontar que sempre, em menor ou maior grau, existe um sujeito em cada indivíduo, e a isto Touraine (2006, p. 121) chama de seu "duplo". O indivíduo se situa na ordem do direito, enquanto seu duplo, o sujeito, na ordem da experiência concreta.

A relação entre esses dois aspectos do ser não é simples, nem facilmente aceito, sem problematizações. Se pensarmos sobre o campo das conquistas sociais, por exemplo, é o devir sujeito, combatente e questionador, que se confronta com as instituições vigentes no sentido de requerer maior liberdade, direitos sociais, econômicos e culturais, ou o que seja, por ora, sua demanda. Por sua vez, como a contrapartida do Estado ou do chefe é a característica da ordem pública, supondo aceitação da demanda solicitada, vem não ao encontro do sujeito, mas sim do indivíduo, visto que o direito adquirido, no caso, não pode abarcar a especificidade de cada ser (o sujeito), apenas de certas classes ou estratos gerais (indivíduos). Relembramos que dentro dessa perspectiva o sujeito é singular, peculiar, íntimo de cada ser; e o indivíduo é massificado, categorizado, coletivizado.

Assim, é o elemento sujeito de cada ser que luta pelos direitos adquiridos para indivíduo. Da mesma forma, se não existissem tais direitos e não fossem garantidos minimamente os espaços do indivíduo, dificilmente existiria a possibilidade do sujeito de cada um se manifestar. É o problema a que refere Touraine (2006, p. 126):

Mesmo que raramente tenhamos a força necessária para defender os direitos do indivíduo contra os da sociedade, experimentamos a mais viva desconfiança no tocante às instituições responsáveis por punir os desviantes ou os criminosos, ou mesmo de cuidar das minorias e dos deficientes. Sempre tememos que o que se chama de interesse da sociedade ignore o direito que cada um tem de ser tratado como sujeito. Se ainda estamos ligados a estas instituições é porque sua presença nos protege da arbitrariedade das ditaduras e da violência, cujo efeito imediato é destruir toda referência de sujeito.

Portanto, a relação existente entre esses dois aspectos, sujeito e indivíduo, apresenta-se como processo complexo de codependência. Dessa forma, não é possível pensar, ou mesmo teoricamente almejar, uma sociedade de plenos sujeitos. Podemos dizer que o indivíduo representa uma plataforma de manifestação do sujeito, assim como o sujeito garante maior ou menor espaço de atuação do indivíduo.

Existem ainda algumas questões a respeito do sujeito que devemos levar em consideração. Primeiramente, o sujeito não se caracteriza como figura secularizada da alma, como presença de uma realidade sobre-humana, divina ou comunitária, mas sim como a força de reivindicação de direitos cada vez mais concretos que protegem particularidades cultu- 
rais. Para que se forme essa consciência de sujeito, Touraine aponta três elementos básicos: 1) uma relação com o si mesmo enquanto ser individual, o que marca uma ruptura com a referência aos princípios universalistas - o sujeito é seu próprio fim; 2) o sujeito não se forma senão entrando conscientemente em conflito com as forças dominantes que lhe negam o direito e a possibilidade de agir como sujeito; 3) cada um enquanto sujeito propõe certa concepção geral de indivíduo.

Vamos nos ater na segunda proposição: "O sujeito não é um puro exercício de consciência, ele tem a necessidade do conflito para que ocorra a ação coletiva" (Touraine, 2006, p. 130). A questão do conflito é de extrema importância na consolidação do sujeito. Podemos pensar que, em momentos anteriores, quando a identidade era determinada pelo grupo ao qual o indivíduo pertencia, a interpelação do fenômeno frente ao conflito caía em certo vazio. Desse modo, a coletividade do grupo assumia o conflito para si de maneira abstrata, como conjunto, sem possibilitar o surgimento do sujeito. A partir do momento em que existe a fragmentação desses grupos, a pulverização das múltiplas possibilidades e a incapacidade de uma identidade ligada unicamente à pertença grupal, o indivíduo antes diluído no grupo torna-se agora uma unidade e, como tal, pode assumir para si o conflito, possibilitando o emergir do seu sujeito.

Respondendo à pergunta sobre como se reconhece o sujeito num indivíduo ou numa coletividade, Touraine (2006, p. 136) afirma: "No engajamento do indivíduo ou do grupo a serviço da imagem dele, mesmo que lhe pareça constituir sua razão de ser, seu dever e sua esperança”. E através dessa perspectiva de conflito e engajamento, o autor aponta ainda que "o sujeito é a convicção que anima um movimento social" (p. 121).

No que se refere à relação do sujeito com tais movimentos, cabe fazer mais alguns apontamentos: 1) negar-se a qualquer possibilidade de atrelar a concepção de sujeito a alguma concepção ideológica específica. Isto seria controverso, pois o sujeito de Touraine não se sente mais à vontade na sociedade do dinheiro e do individualismo do que no imaginário da luta do proletariado. 2) ter cuidado com a tendência a conceber o sujeito através de duas concepções dicotômicas: ou defasado frente à experiência de vida, sempre aquém da realidade, buscando preencher a falta de algo, ou, ao contrário, invocando certa imagem heróica, triunfante, daquele que constrói a realidade em que vive. Deve-se ter cautela, nem tanto o céu, nem tanto a terra, pois, como já apontamos, existe uma constante alternância entre sujeito e indivíduo.

Por fim, é importante apontar que não é possível, dentro desta concepção, realizar outra análise do sujeito que não seja referente ao poder que ele possui ou ao qual é submetido. Sendo assim, as relações de poder caracterizam-se como elemento indispensável para a análise do sujeito. Passamos agora a analisar a relação do ser sujeito com os chamados movimentos sociais, outra categoria bastante desenvolvida teoricamente por Touraine.

\section{O sujeito e os movimentos sociais}

Em razão de seu caráter combatente e de sua estreita ligação com a questão do poder, a figura do sujeito mostra-se como imprescindível para a concepção de Novos Movimentos Sociais (NMS), cujas definições são amplas, como se caracterizam todos aqueles movimentos de coletividade que buscam emancipar-se ou transformar as estruturas vigentes. O movimento social mais radical busca manter a distância que separa o sujeito da máquina social e de seus mecanismos de autocontrole. Nesse sentido, podemos lembrar as grandes greves francesas de 1913, 1936, 1948, maio de 1968, os movimentos civis contra a guerra do Vietnã nos Estados Unidos, a luta que levou Salvador Allende ao poder no Chile, os zapatistas mexicanos - enfim, movimentos que abalaram, em maior ou menor grau e por um determinado tempo, as forças da ordem vigente.

As concepções mais flexíveis a respeito dos NMS são justamente aquelas que agregaram ao embate econômico a dimensão das lutas culturais, rejeitando uma visão funcionalista da cultura como um conjunto fixo de verdades pretéritas a serem seguidas no presente. Além disto, caracterizam-se pela substituição de uma visão de sujeito histórico redutor da realidade pela emergência de um sujeito coletivo difuso, não hierarquizado, crítico e combatente (Gohn, 2004).

Para Guattari \& Rolnik (1993), o que caracteriza os NMS não é somente a resistência contra o processo de serialização da subjetividade, mas também a tentativa de produzir modos de subjetividade originais e singulares, ou processos de singularização, opostos aos processos de massificação. $\mathrm{O}$ que caracteriza o processo de singularização é que ele é autorregulador, não tem um sentido fixo definido de antemão, não é obcecado pelo futuro (salvação sempre vindoura, como na ideia de revolução ou progresso) e prioriza o presente.

Sobre a relação do sujeito com os movimentos sociais, podemos perceber em Touraine que, ao mesmo tempo em que o movimento social eleva o sujeito e seu olhar para além das percepções vigentes, o próprio sujeito converte sua postura em ganhos e benefícios que fortalecem o movimento. Assim se estabelece uma via de mão dupla que se retroalimenta. O sujeito apresenta-se como aquela propulsão de cada 
indivíduo, interpelado pelo social, convidado a lutar pelo reconhecimento de si (sua singularidade) como um ser de direitos.

Contudo, Touraine afirma que não existe a possibilidade de emergência desse sujeito senão na presença de dois aspectos: a interpelação no indivíduo pelo movimento ou pelo fato social e o exame da consciência individual. Sobre este último, é importante ressaltar que se refere, ao longo da formação de cada indivíduo, ao que não foi ensinado, mas sim reprimido (a repressão à rebeldia, ao confronto, ao embate, a discordância etc.). $\mathrm{Na}$ tentativa de resgatar esse sujeito reprimido pelos modos de subjetivação dominante, é necessário, de alguma forma, o acesso à inconsciência.

O sujeito parece encoberto pela banalidade do eu e de sua situação, assim como um livro é encoberto pela areia de uma duna, e não pode mais ser encontrado porque não tem nenhuma comunicação com a areia que o encobre. Isto explica que, o mais das vezes, em nossas vidas, o sujeito está ausente (inconsciente), como se fosse desconhecido. (Touraine, 2006, p. 143)

Dessa forma, o movimento social possui como incumbência despertar o sujeito e é justamente nesse ponto que reside sua força, pois não se trata de um aglutinado de indivíduos massificados, mas sim de um coletivo - potencialmente poderoso - de pessoas despertas que, naquele momento, se propõem a lutar de forma consciente.

Em relação ao âmbito da psicologia, em trabalhos anteriores, afirmamos: "Não podemos pensar os processos de subjetivação como exclusivamente individuais, vividos pelo sujeito na construção de seu mundo interno, mas sim como um processo de socialização, sempre relacional, gerando formas de sociabilidades diversas" (Veronese, 2007, p. 21). O risco de analisar o indivíduo descolado do contexto social, intervindo de forma igualmente desconectada desse contexto, ainda não foi totalmente superado na ciência psicológica. Desse modo, o diálogo com as demais ciências sociais pode em muito contribuir para minorá-lo.

Um dos campos em que esse diálogo tem se mostrado por demais interessante é o da psicologia social, especialmente na área em que atuamos mais diretamente, as análises e intervenções na esfera do trabalho. Cada vez mais se desvendam novas formas de organização no universo do trabalho, formas associativas guiadas pelos princípios da cooperação e da autogestão. Não é possível existir autogestão sem sujeitos. Esses novos movimentos do âmbito laboral não buscam apenas a reinserção dos trabalhadores no mercado formal ou a sustentabilidade de comunidades carentes, mas também carregam, em seus princípios, um potencial transformador. Esses novos movimentos, nascidos das contradições do sistema social vigente e de sua divisão do trabalho, travam embates pela defesa de modos mais sustentáveis de desenvolvimento, pela descentralização do poder nas empresas e empreendimentos, pelas relações diferenciadas com o meio ambiente, pela valorização das culturas locais, propondo uma mudança conceitual nos fundamentos da ordem capitalista. Propõem, por exemplo, a substituição da competição pela cooperação, da individualidade pela solidariedade e da heterogestão pela autogestão. É claro que essa proposição vira prática em graus muito variáveis, e os resultados alcançados são por vezes limitados, mas existe um movimento animado por sujeitos com essa intenção.

$\mathrm{O}$ trabalho caracteriza-se como um (dentre outros) dos elementos de ligação e inter-relação entre o indivíduo com seus iguais e as estruturas sociais que lhes cercam, e também como elemento fundamental para as análises sociais da modernidade (Nardi, 2006). É importante que possamos, através da esfera do trabalho, promover espaços de interlocução entre a dimensão dos indivíduos e dos sujeitos, se ali engendrarem-se relações que permitam a singularização, a criatividade e a luta por melhores condições de existência (Veronese, 2007, p. 24).

Para Santos (2000, p. 56), o que se coloca em jogo atualmente, quando pensamos em sujeitos, indivíduos e movimentos sociais, "é a disputa epistemológica entre dois paradigmas: o hegemônico (forma de conhecimento e racionalidade da ciência moderna, das práticas socioeconômicas capitalistas) e o emergente, que consiste em experimentações que buscam modos diferentes de conhecer, relacionar-se e ser".

Assim, nas esferas do trabalho, doméstica, do lazer, da comunidade ou qualquer outra, existem possibilidades para o emergir do sujeito em cada indivíduo. Quando isto não ocorre, cabe aos movimentos sociais denunciar as estruturas de submissão e assim desacomodar os indivíduos, provocando movimentos coletivos em busca de certos embates que propiciem melhoria das condições atuais, minimização das desigualdades, busca por direitos mais sólidos ou outras demandas relacionadas à luta contra os processos de submissão.

\section{Elaborações parciais sobre o tema}

Como este artigo não pretende esgotar a temática que aborda, mas, pelo contrário, busca levantar questionamentos a serem aprofundados, no título desta seção "Elaborações parciais" iremos apontar autores e teorizações que acreditamos poder em muito contribuir com o avanço desta reflexão, para trabalhar em textos futuros e como sugestão para outros estudiosos do tema.

A discussão a respeito do sujeito e do indivíduo assume diversos contornos e complexas possibilidades. 
De momento, para este texto, ficam pendentes aprofundamentos referentes aos aspectos mais específicos a respeito da influência da cultura, à concepção foucaultiana de poder e suas fundamentais distinções entre as sociedades disciplinares e as sociedades de controle. De alguma forma, representam a transição dos modos de controle de uma sociedade, em grande escala composta por indivíduos, para uma outra formada por sujeitos e indivíduos, assim como as contribuições de Laclau \& Mouffe (1987) sobre os conceitos de subordinação e opressão. Contudo, atingimos o que se propunha para este trabalho ao explicitarmos as distinções propostas por Touraine a respeito do sujeito e do indivíduo, bem como o envolvimento de cada um em relação aos movimentos sociais.

Como podemos perceber, a partir da análise contextual proposta no início deste texto, Touraine dá um passo importante em busca de uma forma de análise social diferenciada, coerente com a transição paradigmática de Santos $(2000,2006)$, e de outras tantas que surgiram nas últimas décadas. Trata-se de tentativas de aproximações mais complexas a essa realidade multifacetada do sujeito e da relação indivíduo-sociedade, cerne das Ciências Sociais. Ao propor uma análise social a partir da figura do sujeito, e não mais da história como personagem principal, Touraine assume uma postura relativista, eventualmente negando os discursos universalizantes que enfatizaram as grandes estruturas sociais. Ao mesmo tempo, ao caracterizar o sujeito como combatente, crítico e político, também se contrapõe à postura por vezes "vitimizada" do indivíduo moderno, que foi concebido como se estivesse submetido a condições necessárias.

O sujeito, como vimos, surge a partir do interpelamento do indivíduo por um fenômeno social que, de alguma forma, encontra reverberações em seu consciente/inconsciente e, movido por um processo de voltar-se a si mesmo em busca de referências, acaba por engajar-se no processo de embate. A relação entre sujeito e indivíduo constitui-se como processo de alternância dinâmica, onde por vezes o indivíduo caracteriza-se, através de seus direitos, como plataforma de manifestação do sujeito; por outras, o sujeito é quem emerge garantindo direitos peculiares para esse indivíduo que não se adequou mais aos discursos totalizantes das instituições sociais vigentes.

Da mesma forma, percebemos como se mostra importante o emergir desse sujeito para os NMS. Melhor dizendo, como é importante aos NMS colocarem-se de forma atenta em relação a esse sujeito existente em cada indivíduo, pois é este que anima e fortalece tal movimento.

Todos esses aspectos nos levariam a compreender a postura de Touraine, assim como o emergir desse sujeito, como uma concepção pós-moderna de perceber a realidade social. Contudo, seria interessante também submeter seus pressupostos à crítica, que ele próprio considera tão fundamental para fazer avançar as Ciências Sociais. Se analisarmos em profundidade seus escritos, poderemos avaliar que a concepção proposta de sujeito ainda carrega nuances de algo essencial, algo que, a priori, estaria adormecido em cada indivíduo. Apesar de todas as desamarras frente às concepções vigentes propostas por Touraine, encontra-se, em sua proposta de sujeito, certo aspecto de essência, que de alguma forma poderia vinculá-lo a características das análises consideradas modernas.

Neste ponto é necessário estarmos atentos justamente para os apontamentos iniciais deste texto: a relação entre uma postura moderna e outra pós-moderna não se caracteriza por um processo direto, fechado e linear; pelo contrário, é aberto a contradições e flexível a reformulações.

Mas o que de fato encontramos de mais comum entre os autores que se debruçam sobre o tema do sujeito na contemporaneidade é esse aspecto combatente, militante, ativo, engajado que faz dele, muitas vezes, o maior protagonista do campo social:

A tentativa de controle social, através da produção de subjetividade em escala planetária, se choca com fatores e resistência consideráveis, processos de diferenciação permanentes que eu chamaria de revolução molecular. Mas o nome não importa. A revolução molecular consiste em produzir as condições não só de uma vida coletiva, mas também de encenação da vida para si próprio, tanto no campo material quanto no campo subjetivo. (Guattari \& Rolnik, 1993, p. 46)

A revolução molecular passa pela capacidade de apropriar-se, participar na produção dos meios de comunicação, transformar cotidianamente as instituições de ensino, enfim, constituir uma série de ferramentas que possam produzir o sujeito engajado na demanda coletiva e, ao mesmo tempo, autorreferenciado. Adotar uma concepção na qual o sujeito combatente e questionador é engendrado pelas contingências da realidade que o cerca em nada elimina a importância do que Touraine denominou "voltar-se para si". Pelo contrário, a sugestão touraineana de voltar-se para si coloca-se como importante estratégia na produção das revoluções moleculares de Guattari \& Rolnik.

O sujeito é produzido na intersecção com a cultura e, assim sendo, seu tempo será o presente, possibilitando a luta por uma ordem social pautada a um tempo pela diferença e pela singularidade, no reconhecimento das múltiplas realidades existentes no social. Há um sujeito a ser produzido por cada indivíduo e isso abre um amplo leque de possibilidades de mudança social que, em última instância, reaviva a esperança no presente e no futuro. 


\title{
Referências
}

GADEA, C. Teorias sociais contemporaneas. Programa de Pós Graduação em Ciências Sociais da UNISINOS, 2007. Disponível em: <http://www.unisinos.br/pastanet/ $\operatorname{arqs} / 1369 / 3439 /$ teoria_social_paradigmas_sociologicos. ppt>. Acesso em: 19 nov. 2008.

GOHN, M. da G. Teoria dos movimentos sociais. Rio de Janeiro: Loyola, 2004.

GUATTARI, F.; ROLNIK, S. Micropolítica: cartografias do desejo. Petrópolis: Vozes. 1993.

JOVCHELOVITCH, S. Psicologia social, saber, comunidade e cultura. Revista Psicologia e Sociedade, São Paulo, v. 16, n. 2, p. 20-31, maio/ago. 2004.

LACLAU, S.; MOUFFE, C. Hegemonia y radicalización de la democracia. Hegemonia e estrategia socialista: hacia uma radicalización de la democracia. Madrid: Siglo XXI, 1987.

LIPOVÉTSKY, G. A sociedade da decepção. São Paulo: Manole, 2006.

MAFFESOLI, M. Sobre o nomadismo: vagabundagens pós-modernas. Rio de Janeiro: Record, 2001.

NARDI, H. Subjetividad y economia solidária: desafios para la constituicion de si en la instabilidad de la supervi- vencia cotidiana. In: VERONESE, M. Economia solidaria e subjetividad. Buenos Aires: Altamira, 2007. p. 135-174. Ética, trabalho e subjetividade. Porto Alegre: Ed. UFRGS, 2006.

REIS, E. P. Reflexões sobre o homo sociologicus. Revista Brasileira de Ciências Sociais, n. 11, p. 23-33, 1989.

SANTOS, B. A crítica da razão indolente: contra o desperdício da experiência. Porto: Afrontamento, 2000.

SANTOS, B. A gramática do tempo: para uma nova cultura política. São Paulo: Cortez, 2006.

TOURAINE, A. El sujeto. Un nuevo paradigma para comprender el mundo de hoy. Buenos Aires: Paidós, 2006. VERONESE, M. Subjetividade, trabalho e solidariedade. Canoas: Aletheia, 2006.

VERONESE, M. (Org.). Economia solidaria y subjetividad. Buenos Aires: Altamira, 2007.

VERONESE, M. V.; GUARESCHI, P. A. Possibilidades solidárias e emancipatórias do trabalho: campo fértil para a prática da psicologia social crítica. Psicologia e Sociedade, São Paulo, v. 17, n. 2, p. 58-69, 2005.

\section{The subject and the individual under Alain Touraine's perspective}

\begin{abstract}
The article aims to discuss, mainly under Alan Touraine's latest perspective, the development of subjectivation processes in contemporaneity. One tries to understand how current changes in the way of perceiving and being in the world influence the constitution of each individual. For that, we analyze how the author differs the concepts of Individual from Subject, as well as the relevance of their relation with social movements and struggles for emancipation, performed by many groups and communities.
\end{abstract}

Key words: individual; subject; social movements.

\section{El sujeto y el individuo en la perspectiva de Alain Touraine}

\section{Resumen}

El artículo procura discutir, a partir de la perspectiva más reciente de Alain Touraine, el desarrollo de los procesos de subjetivación en la contemporaneidad. Se busca comprender como los cambios actuales en la forma de percibir y estar en el mundo que influencian la constitución del sujeto. Para eso, analizamos de qué manera el autor distingue los conceptos Individuo y Sujeto, así como la importancia de la relación existente entre la subjetividad humana en sus manifestaciones singulares y los movimientos sociales y luchas por emancipaciones, protagonizadas por los diversos grupos y comunidades.

Palabras clave: indivíduo; sujeto; movimientos sociales 